The causes of long waiting-lists for admission to hospital or for delays in its outpatient and other departments have often enough been discussed ${ }^{1-6}$ and remedies ranging from the startlingly obvious to the statistically recondite proposed. While $x$-ray departments, pathology laboratories, and operating-theatres, together with the highly skilled staff to man them, are scarce now and likely to remain so for years, some delay is inevitable. It is aggravated by the irregularity in both the numbers and the urgency of the demands made on these services. But perhaps the most generally helpful remedy is for a senior member of the staff to have the special obligation of periodically reviewing the matter in his hospital. Local resources and the demands made on them vary so greatly that the man on the spot-provided he is charged with the task-can see straightaway what can easily escape the inquirer bustling along from afar with his slide-rule.

Though more consultants, together with ancillary staff and equipment, are needed in many specialties if a faster service is to be given, only a fragmentary and sometimes misleading estimate of how well a hospital is discharging its responsibilities will be gained from statistics of bed turn-over, patient through-put, and such-like. For the great majority of people in them hospitals are to a certain extent refuges. Moreover, the urgency of their need varies enormously, and the medical man has to balance claims for admission on clinical grounds that are often not apparent to patients. Here it may be admitted that fuller explanations should sometimes be given than are customary.

\section{Cancer and Asbestos}

By the time of the first International Conference on the Biological Effects of Asbestos held in New York at the end of $1965^{1}$ it was clear that asbestos workers are at special risk of developing cancers of at least two types-bronchial carcinoma and mesothelioma. The epidemiological data then available suggested that the risk may be associated particularly with exposure to crocidolite asbestos, and it was uncertain whether the other two main types of fibre, amosite and chrysotile, are similarly hazardous. ${ }^{2}$ Several factors, some of them operating in opposite directions, obscure the picture. Thus, while the number of persons exposed to asbestos dust has been increasing, ${ }^{3}$ standards of protection of workers have been improving. In countries such as the United Kingdom that import asbestos it has been common for workers to be exposed to dusts from all three types of fibre.

Asbestosis and asbestos-induced cancer compete as causes of death, and under conditions of poor dust control asbestosis tends to kill before the minimum induction time for cancer has elapsed. According to W. D. Buchanan ${ }^{4}$ in males the average age at death from asbestosis rose from 49.3 years during 1924-40 to 60.4 years during 1961-3. During the same period the percentage of men with asbestosis who also developed lung cancer or mesothelioma rose from 19.7 to the alarming figure of 54.5 , though the average age at death in cases with both conditions remained almost constant at between 54.3 and 57.6 years. Another problem left somewhat in the air at the 1965 Conference was whether exposure to asbestos increases the risk (f gastrointestinal cancer. ${ }^{5-7}$ So far there has been no real corroboration that it does.
At the end of April the second International Conference on the Biological Effects of Asbestos was held in Dresden. Since 1965 workers in many countries have confirmed the association between occupational exposure to asbestos and mesothelioma. Notable in this regard are recent studies in Scotland ${ }^{8}$ and Newcastle upon Tyne. ${ }^{9}$ Technical improvements have allowed asbestos bodies to be detected in the sputum of about $50 \%$ of males in certain industrial cities. ${ }^{10}$ Clearly therefore the mere detection of asbestos in the lungs cannot mean that it is necessarily a prelude to lung cancer or mesothelioma. Only when quantitative methods showed the presence of large numbers of fibres, as in the Scottish survey, ${ }^{8}$ may aetiological significance be attached to the finding. Fortunately for the purposes of measurement it seems that inhaled asbestos is distributed fairly evenly throughout the lungs, ${ }^{11}$ so that any block of lung tissue may be regarded as representative of the whole. This is particularly important in relation to retrospective studies. A possible snag in all studies, however, is that it now seems that fibrous materials other than asbestos may give rise to the formation of structures very similar to asbestos bodies. According to P. F. Holt ${ }^{12}$ at the University of Reading the iron in the ferritin which is a main constituent of the asbestos body is derived from haemoglobin resulting from mechanical damage to the tissues by fibres. A more generally accepted view is that the iron is derived from the fibre itself by a process of leaching out by tissue fluids.

Mesotheliomas have been induced in animals by the administration of asbestos. ${ }^{13-15}$ W. E. Smith reported at the recent conference that he and his colleagues had succeeded in inducing pulmonary carcinomas in hamsters by the intratracheal instillation of a mixture of chrysotile asbestos and 3,4-benzpyrene. The asbestos alone was without neoplastic effect, whilst the benzpyrene alone induced only tracheal and bronchial papillomas. This finding is reminiscent of that of Shabad ${ }_{2}^{16}$ in Moscow, who conducted rather similar experiments in rats with mixtures of benzpyrene and India ink, and

Whipple, H. E., and van Reyen, P. E., Ann. N.Y. Acad. Sci., 1965, $132,1$.

2 Wagner, J. C., Ann. N.Y. Acad. Sci., 1965, 132, 575.

Gilson, J. C., Ann. N.Y. Acad. Sci, 1965, 132, 696.

- Buchanan, W. D., Ann. N.Y. Acad. Sci., 1965, 132, 507.

Selikoff, I. J., Churg, J., and Hammond, E. C., F. Amer. med. Ass., 1964, 188, 22.

- Mancuso T. F., Ann. N.Y. Acad. Sci., 1965, 132, 589.

- Selikoff, I. J., Hammond, E. C., and Churg, J., Y. Amer. med. Ass.,

- Gibson, A. A. M., McEwen, J., Finlayson, Angela, and Mair, A., Epidemiology of Mesothelioma in Scotland. Contribution to II Interdemiology of Mesothelioma in Scotland. Contribution to I Internation 1968 .

- Ashcroft, T., Brit. med. F., 1968, 1, 614

Anjilvel, L., and Thurlbeck, W. M., Canad. med. Ass. F., 1966, 95 , 1179.

1 Elmes, P. C., and Bell, D., Frequency of Distribution of Asbestos Bodies Within the Lung. Contribution to II International Conference on the Biological Effects of Asbestos, Dresden, 1968.

12 Holt, P. F, and Botham, J. The Development of Asbestos Bodies. Contribution to II International Conference on the Biological Effects Contribution to II Internation

13 Wagner, J. C., in Lung Tumours in Animals, ed. L. Severi, 1966, p. 589 . Perugia.

14 Smith, W. E., Miller, L., Elsasser, R. E., and Hubert, D. D., Ann N.Y. Acad.' Sci., 1965, 132, 456.

15 Roe, F. J. C., Carter, R. L., Walters, M. A., and Harington, J. S., Int. F. Cancer, 1967, 2, 628

16 Shabad, L. M., F. nat. Cancer. Inst., 1962, 28, 1305.

17 Saffiotti, U., Cefis, F., and Shubik, P., in Lung Tumours in Animals, ed. L. Severi, 1966, p. 537. Perugia.

18 Harington, J. S. Ann. N.Y. Acad. Sc. 1965, 132, 31

19 Roe, F. J. C., Walters, M. A., and Harington, J. S., Int. F. Cancer, $1966,1,491$.

20 Haries $\mathrm{P}$. The Prevention of Asbestosis in Naval Dockyards. Contribution to II International Conference on the Biological Effects Contribution to II Internatio

${ }_{11}$ Roach, S. A., Problems Concerned with Establishing Hygiene Standards for Asbestos. Contribution to II International Conference on the Biological Effects of Asbestos, Dresden, 1968. 
that of Saffiotti and his colleagues, ${ }^{17}$ who induced pulmonary tumours with mixtures of haematite and benzpyrene. It also reawakens interest in the fact that some forms of asbestos in the natural state contain mineral oils, and that all forms are liable to become contaminated with mineral oils during processing or storage. ${ }^{18}$ Such oils are carcinogenic. ${ }^{19}$ Moreover, I. J. Selikoff and colleagues have concluded from studies in man that cigarette smokers who are occupationally exposed to asbestos have eight times the risk of dying of bronchial carcinoma as cigarette smokers in other occupations. $^{7}$ These observations suggest that asbestos dust and cigarette smoke act synergically in the induction of pulmonary cancer.

If the mechanism of carcinogenesis by asbestos remains an enigma, there is no doubt that we must learn to live safely in association with this indispensable mineral. Here a notable contribution was made at the recent conference by P. G. Harries. ${ }^{20}$ A logical analysis of the problems of asbestos exposure in relation to ship building and ship breaking in the Naval dockyards at Devonport led to a variety of special measures to reduce unnecessary exposure to asbestos, including the use of alternative materials and the design of elaborate, but practical, protective clothing. It is to be hoped that all shipyards in this and other countries, and other establishments with similar asbestos exposure problems, will not be slow to take advantage of the lead given by this work. It is also to be hoped that serious consideration will be given to the recommendation of the British Occupational Hygiene Society that hygiene standards should be based on exposure over the working lifetime. According to calculations presented at the conference by S. A. Roach, ${ }^{21}$ if the product of the number of fibres of chrysotile asbestos per c.cm. in the working atmosphere and the number of years of exposure does not exceed 100 fibre-years, the risk of the development of clinical signs of asbestosis is less than $1 \%$. In practice this standard is far more stringent than that currently accepted by the U.S. Public Health Service and that operating in many industries throughout the world. It is a problem for the future to know whether these calculations, which concern the risk of asbestosis from chrysotile asbestos, apply also to amosite and crocidolite. It is also a problem to know whether the compromise is acceptable in relation to the risk of mesothelioma and carcinoma of the lung.

\section{Declaration of Sydney}

Not surprisingly the statement on the diagnosis of death-or, as it will probably be best known, the Declaration of Sydney -which the 22nd World Medical Assembly adopted at its final session on 9 August captured the attention of the press. While it certainly will not satisfy everyone, especially doctors, who want an exact assessment of the signs of death, it probably goes as far as can at present be expected from a world body. It was backed by an assurance that as soon as future studies allow a statement will be prepared on the physical signs themselves. The text of the Declaration, together with a general account of the proceedings of the Assembly in Sydney, is given at page 493.

The Declaration affirms that the legal responsibility for determining death should remain the physician's, as is the practice in most countries, and states that under ordinary circumstances the classical criteria are enough. By so doing it immediately reduces the area of public doubt and anxiety to those cases in which artificial means of resuscitation are either in use or contemplated or in which the transplantation of an organ is being considered. Furthermore it puts no fresh obstacle in the way of ordinary death certification. Certainly it would be a disservice unnecessarily to complicate this procedure, for that could only add to the distress of relatives.

In resuscitation and transplantation, however, time is usually critical. Here the Declaration of Sydney does well to emphasize that it is the moment of irreversibility of the processes leading to death which must be determined rather than the moment of death. The latter defies exact definition; it varies organ by organ, cell by cell, so that it is impossible to say precisely when human life becomes extinct.

The Declaration states that while at present the electroencephalograph is the most helpful diagnostic aid " nq single technological criterion is entirely satisfactory." In reaching this conclusion those who drafted the statement were influenced by the reports of flat encephalograms for hours or even days which have been followed by recovery. The most recent of these was in a letter to this journal from the Regional Poisoning Treatment Centre at Edinburgh. ${ }^{1}$ This noted that of 12 deeply unconscious patients suffering from poisoning by central nervous system depressants 5 had had flat E.E.G. tracings for up to 11 hours and all but one had made a full clinical recovery. Such findings add force to our earlier comment $^{2}$ that little work had been done in Britain to evaluate the contribution of electroencephalography to assessing the consequences of cardiac arrest, and also to G. Pampiglione's plea $^{3}$ for a working group to reconsider our present knowledge in the borderland between life and death. It is clearly urgent that the contribution which the E.E.G. can make as an indicator of cerebral death should be established. Studies of the other technical aids most commonly used in diagnosing death should also be undertaken, under varied clinical circumstances and at different ages. The fact that the viability of transplantable organs falls off so sharply after obvious clinical death of the patient ${ }^{4}$ makes such studies all the more necessary.

Finally the Declaration makes it mandatory that with potential donors death should be diagnosed by " two or more physicians ... in no way ... immediately concerned with the performance of the transplantation." In the original draft before the meeting, after a reference to transplantation, the final decision that death had occurred was left to " the overall judgement of the physician either alone or in consultation with colleagues." Patently this gave insufficient safeguard, and the revised wording, proposed by the British delegation, was readily accepted. It is now in line with recommendations adopted by the Minister of Health's conference in March and by the B.M.A.'s Committee on Medical Science, Education, and Research, ${ }^{6}$ and should help dispel any remaining fears of the public concerning possible collusion between doctors making these difficult and delicate decisions. No one supposes that the Declaration of Sydney will be the last word on the subject, but it does usefully clear the ground for the technical guidance now so much needed.

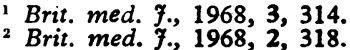

2 Brit. med. 7., 1968, 2, 318.

- Brit. med. F., 1968, 2, 557.

s Brit. med. F., 1968, 1, 833.

- Brit med. F. Suppl., 1968, 3, 47
} 